year, as a classroom assignment at Georgetown, I proposed that each student write an essay on the discovery, orbital features, and mythological background for 2 or 3 of the newly discovered satellites in the planetary system. Several said it stimulated them to do similar research on other satellites. It was fun; I enjoyed reading the essays and let all the students share the findings of their fellows.

H.S. Gurm: In reference to Professor McCarthy's remarks:

1. Wentzel's "traditional" model differentiates the American pattern of education from that of other countries. It is not concerned with the classical pattern in which everything was taught through language or grammar. As such, it should not be confused with the latter.

2. The third world has its own cultures; there is no such thing as an under-culture or an over-culture. The question is not teaching culture or "the classics" through astronomy or vice versa. Both need to be covered independently. Teaching astronomy through culture and vice versa would dilute the teaching of astronomy, and would affect the conceptual learning of it.

B. Curran: Should there be greater use of the humanities in astronomy classes or greater use of astronomy in humanities classes?

N.S. Nikolov: My paper deals with the problem of how it is possible to teach human culture by teaching astronomy, i.e., with astronomy classes. But I think the problem may be reversed; it is also possible to teach astronomy in the humanities classes.

\title{
INTERDISCIPLINARY APPROACHES TO ASTRONOMY
}

Andrew Fraknoi

Astronomical Society of the Pacific, 390 Ashton Ave, San Francisco, California 94112, U.S.A.

To understand the motivation for my talk, you must bear in mind what Don Wentzel discussed so eloquently at the beginning of the colloquium. In the U.S., the vast majority of students taking astronomy classes at the college level are not science majors. Many students coming into the astronomy courses are afraid and distrustful of science and often see science as a very alien endeavor, quite separate from their everyday lives and other studies.

For such students, it can sometimes be very reassuring and enlightening to show some interesting connections between astronomy and other (nonscience) fields at a few places in the introductory astronomy course. For example, many students are surprised and excited to see the inspiration that astronomy has provided for music, literature, and art and some of the interesting connections between astronomy and psychology, archaeology, and law. 
But the idea behind teaching and exploring interdisciplinary connections is more than merely doing therapy for science anxiety. I also believe that there is a danger in the college or university "catalog" model of human knowledge, in which everything is divided into departments whose members speak to the members of other departments as rarely as possible. In reality, one's understanding and appreciation of science and the humanities becomes a complex mental blend, in which the pleasures of hearing a symphony and learning about a new scientific model can be very similar.

Using interdisciplinary approaches in our teaching can also serve to remind our students (and ourselves) that it is so often the cross currents and cross fertilization that lead to progress in many fields. As the great Russian-American novelist Vladimir Nabokov said, "There is no science without fancy, no art without facts."

In this brief review, I would like to mention just a few examples, both from serious and popular culture, for your edification and amusement. A reading list of useful sources for further exploration can be found at the end of this paper.

\section{Science Fiction}

If you think that science fiction is still about daring young men saving both the Earth and the mad scientist's beautiful daughter from ravaging aliens, it may be time for another look. Today, there are many authors writing sensitive, literate science fiction based on the extrapolation of good science. Some of their best sciencerelated works are not only interesting in their own right but also can help students visualize and internalize some of the more abstract notions of modern science. A few of my favorite authors include:

\section{a) Gregory Benford}

Benford is a plasma physicist at the University of California at Irvine and arguably one of the finest observers and interpreters of science in modern fiction. Not only is his novel Timescape an exciting yarn about ecological disaster and communication backwards in time using tachyons, but also it has one of the most realistic portraits of a scientist I have ever read. Astronomers might also enjoy finding colleagues such as Fred Hoyle, Geoff and Margaret Burbidge, and others in the book.

Benford's two other recent novels, In the Oceans of Night and Across the Sea of Suns, posit a fascinating hostile universe in which powerful machine intelligences rule and organic life-forms are hunted and destroyed. A new novel, Great Sky River, envisions a future near the center of the Milky Way, where small bands of humans endure constant flight from hordes of destructive machines.

\section{b) Larry Niven}

Although he is not quite the stylist that Benford is, Niven's stories scintillate with ideas inspired by modern astronomy. In several of his short stories, massive or quantum black holes have been used to good effect. In World Out of Time, for example, a supermassive black hole near the galactic center allows the protagonist 
to travel three million years into the future. In the Integral Trees and The Smoke Ring, he creates a world of living beings in a gas torus in orbit around a neutron star.

\section{c) Charles Sheffield}

Sheffield has a Ph.D. in physics and many of his short stories (collected in Vectors and Hidden Variables) involve illustrating and fleshing out new ideas in astrophysics. In his novel Between the Strokes of Night, he suggests an imaginative form of life in intergalactic space.

\section{d) John Varley}

Varley is an excellent writer who is as comfortable describing the conditions on Venus as he is examining the social effects of genetic engineering . His first novel, The Ophiuchi Hotline, is a tour-de-force, with enough ideas and themes to make several books, including the sport of mini-black-hole hunting.

\section{e) Fred Pohl}

Veteran science-fiction writer Pohl has written many interesting works of hard science fiction and social extrapolation. His Man Plus describes how humans could be biologically engineered to survive on Mars. In Gateway, an award-winning novel that is a favorite with my students, Pohl describes what must surely be the first case of "black hole guilt" in literature.

\section{f) David Brin}

Brin has a Ph.D. in astrophysics from the University of California, San Diego, and writes mostly about an old science fiction theme, the problems and possibilities in contacting life elsewhere, but with stories and novels based on an understanding of the real universe. His award winning story "The Crystal Spheres" has advanced races using time dilation near black holes to bear the loneliness of a universe in which life is still rare.

\section{Astronomers Writing Science Fiction}

In the last few years, a number of working astronomers have joined a long-time science fiction author Fred Hoyle in combining science and fiction writing. Carl Sagan has written the best seller Contact, about the consequences of a message from an extraterrestrial civilization. (Sagan, by the way, asked Kip Thorne and his students at Caltech to design a viable black hole interstellar transportation system for his novel.)

Supernova expert J. Craig Wheeler has written a thriller entitled The Krone Experiment, which involves mini black holes. Donald Clayton's Joshua Factor interweaves neutrinos and intrigue. British physicist Paul Davies works out the consequences of the large-scale arrival of antimatter from space in his novel Fireball. 
NASA's William Rossow has worked with M. Bradley Kellogg on two novels, The Wave and the Flame and Reign of Fire, that take place in a very alien environment. And physicist Robert Forward has invented a life-form that can live on a neutron star, in his novels Dragon's Egg and Starquake.

Although many astronomers have enjoyed and recommended Fred Hoyle's The Black Cloud, in which astronomers take the reins of power as the Earth faces disaster, my favorite among Hoyle's novels is October the First Is Too Late, a fictional working out of the consequences of the "many worlds" interpretation of quantum mechanics.

\section{Poetry}

Astronomy has served as inspiration for poetry for centuries and in courses tracing the evolution of astronomical ideas it can often be fascinating to see that evolution in the poetry of each era as well. (Some specific suggestions can be found in the interdisciplinary packet from the A.S.P., listed in the Resources at the end.)

Among modern poets who use astronomy and physics to particularly good effect in their work, it might be worth mentioning two of my favorites. Diane Ackerman studied astronomy with Carl Sagan at Cornell; her collection The Planets is a beautiful (and informed) evocation of the solar system as we understand it today. Novelist John Updike enjoys and keeps up with modern science and has written poems about neutrinos, the satellites of Jupiter, and entropy. (See, for example, his collection Facing Nature.)

Some anthologies and articles to make a start in this field might include:

Gordon, B. Songs from Unsung Worlds: Science in Poetry. 1985, Birkhauser Boston.

Marschall, L. "Modern Poetry and Astronomy" in Mercury, Mar/Apr. 1983, p. 41. Phillips, R., ed. Moonstruck: An Anthology of Lunar Poetry. 1974, Vanguard Press. Vas Dias, R. Inside Outer Space. 1970, Doubleday/Anchor.

\section{Mainstream Literature}

Astronomy and physics have begun to play an increasingly important role in modern literature, as the ideas from science begin to permeate other branches of human culture and leave an imprint. Through the work of popularizers of astronomy (starting with Jeans and Eddington in the earlier part of our century) a number of writers with little formal training in the sciences have learned enough to incorporate some of the most exciting ideas and themes into their work. Again, let me select just a few examples; more can be found in the sources listed in the Appendix.

The reclusive American writer Thomas Pynchon, who worked at Boeing for a while, has written a number of novels and stories using concepts from thermodynamics and other branches of physics, including The Crying of Lot 49 and Gravity's Rainbow. Joyce Carol Oates has done an effective character study using black hole images in a short story entitled "Passions and Meditations" (in The Seduction and Other Stories). 
Lawrence Durrell's Alexandria Quartet (consisting of the novels Justine, Balthazar, Mountolive, and Clea) uses notions from the theory of special relativity to deepen his considerations of modern love and mid-Eastern politics. Italo Calvino constructs modern fables and allegories from scientific notions in Cosmicomics and Tau Zero. Tom Bezzi describes the life and work of Edwin Hubble through the eyes of a fictional granddaughter in Hubble Time. And an astronomer's life and relationships form the core of the novel called First Light by Charles Baxter that winds backward through time.

\section{Music}

Over the last decade and a half, my students and I have collected over 100 examples of music inspired by astronomy. We exclude pieces whose connection with astronomy is peripheral or superficial - there are countless songs one could list extolling the romantic virtues of the full moon, for example - and concentrate only on pieces that are inspired in some way by specific astronomical ideas and discoveries. A good annotated list can be found in my two articles in Mercury magazine (May/June 1977, p. 15 and Nov/Dec. 1979, p. 128) but a few examples will serve to give the reader the flavor of what is now available on records:

In the 1970's Willie Ruff and John Rodgers (a geologist and professor of music at Yale) reconstructed Kepler's "music of the spheres" by converting the motion of the planets as we know them today into musical notes that could be played electronically. The full story is told in their article in American Scientist, May/June 1979 , p. 286, and a recording was available from authors for a while. A similar piece, incorporating the motion of the Galilean satellites of Jupiter, was commissioned by the Münster Astronomical Society for the 350th anniversary of Kepler's death; entitled The Harmony of the World of Jupiter by Gunter Bergmann, it is available on a Schwann label recording.

In 1973, to celebrate the Copernicus Quincentenary, the National Academy of Sciences and the Copernicus Society of America commissioned a piece from astronomer Fred Hoyle and Composer Leo Smit entitled Copernicus: Narrative and Credo. Available on Desto records, the piece features excerpts from the life of Copernicus and a thought-provoking statement of belief from the perspective of modern astronomy.

Karlheinz Stockhausen, a iconoclastic modern composer, has put together (composed really isn't the right word) an intriguing piece called YLEM that is based on the oscillating universe. (YLEM was Aristotle and George Gamow's term for the primordial material from which the present universe was born.) In the piece, which is available on a Deutsche Grammophon recording, 19 players play a big bang, after which ten of the players "expand" away from the stage and move throughout the hall. Later they return, another explosion is played, and the players then leave the building entirely. (The music is - to put it delicately - not easy to listen to, particularly because specific notes have not been written down by the composer, who expects the players to be "in telepathic communication." But the idea of the piece does hold a certain fascination for astronomers.) 
There are many other pieces of serious music that astronomers might enjoy: Philip Glass' opera Einstein on the Beach uses aspects of Einstein's life and work as mantras in a meditative piece of minimalist music; Charles Dodge's Earth's Magnetic Field is a piece whose notes are determined by the $\mathrm{K}_{p}$ index of terrestrial magnetism for the year 1961; and Paul Hindemith's 1947 opera, The Harmony of the World, chronicles the life of Kepler.

In the realm of popular music, there are many pieces based on astronomical ideas, although few of the fans who listen to the music are likely to be aware of the connections. Three songs compare the dying of a love affair or a rock career to the dying of a star: Pink Floyd's "Shine on You Crazy Diamond" (on the album Wish You Were Here), Labelle's "Black Holes in the Sky" (on Phoenix), and Rush's "Cygnus X-1" (on A Fare Well to Kings). Vangelis Papathanassious, who composed the theme song to Carl Sagan's television program Cosmos, has an album entitled Albedo 0.39, which includes pleasant musical pieces with titles like "Main Sequence" and "Sword of Orion."

But probably the most unusual rock record we have seen is an album with the provocative title $H$ to $H e$ Who Am the Only One, by a group that calls itself Van Der Graaf Generator. The album cover explains, "The fusion of hydrogen nuclei to form helium nuclei is the basic exothermic reaction in the sun and the stars, and hence is the prime energy source in the universe." This statement is followed by the three equations of the p-p chain, certainly a first for a rock music album. (For those whose collections would not be complete without this record, it was available on the Dunhill label.)

\section{Other Fields}

The above are just a few areas outside science in which there are interesting connections to be made with astronomy. Connecting threads can be found to many other fields as well:

In art, many serious and popular artists have been inspired by the work of modern astronomers. Among the serious ones, few have produced work of such immediacy and interest as the Mexican surrealist painter Remedios Varo, whose images have appeared in Thomas Pynchon's novel The Crying of Lot 49 and on the cover of at least one popular-science book. Many astronomers have used the mathematically oriented etchings of M.C. Escher in their courses. And astronomer William Hartmann, who is an excellent artist, has produced a number of informed and beautiful works that combine science and imagination.

In psychology, the moon illusion, the panic during Orson Welles' 1938 broadcast of War of the Worlds, and the intensity of belief in UFO's are all interesting topics for investigation. In law, students often enjoy looking at the trials of Giordano Bruno and Galileo and at the influence of Hubble's legal training on his later astronomical work. In archaeology, ancient monuments in Europe and western America have revealed a much greater astronomical interest and sophistication among earlier civilizations than standard histories give them credit for. 


\section{Concluding Comments}

While no one is suggesting that such an approach substitute for a thorough grounding in science and scientific methodology in introductory astronomy courses, it can be very rewarding for the instructor and the student to consider the connections between astronomy and other fields on at least a few occasions and to show how our science fits into the wider range of human culture and thought. The few minutes devoted to a story, poem, or piece of music during an astronomy class could make a deeper impression on your nonscience students in the long run than the world's most exciting lecture on spectral classification.

\section{Resources for Interdisciplinary Approaches to Astronomy}

Digby, J. and Brier, B., eds. Permutations: Readings in Science and Literature. 1985, Morrow. An eclectic collection of excerpts and poems.

Dubeck, L., et al. Science in Cinema. 1988, Teachers College Press. An introduction to teaching science through science fiction films.

Fraknoi, A., et al. Interdisciplinary Approaches to Astronomy. 1986, Astronomical Society of the Pacific. A 32-page collection of articles from Mercury magazine on astronomy and music, poetry, science fiction, etc. Includes a 4-page detailed reading list.

Fraknoi, A. Universe in the Classroom. 1985, W.H. Freeman. Features suggestions for interdisciplinary paper and discussion topics and more detailed reading suggestions in every field of introductory astronomy.

Friedman, A. "Contemporary American Physics Fiction" in American Journal of Physics, May 1979, p. 392.

Friedman, A. and Donley, C. Einstein as Myth and Muse. 1985, Cambridge U. Press. A fascinating examination of Einstein as symbol for science and genius in our time, with excellent sections on the influence of Einstein's work on the humanities.

Nicholls, P., ed. The Science Fiction Encyclopedia. 1979, Doubleday.

\section{Discussion}

J.-C. Pecker: I tend to be afraid of the use (perhaps abuse) of reference to science fiction although I occasionally refer to it myself in my astronomy lectures. S.F. can indeed lead to bad misconceptions! By contrast, detective stories, because of their type of strict logic, help to understand the scientific type of reasoning.

A. Fraknoi: An interesting detective novel influenced by quantum mechanics is Stanislav Lem's The Investigation. A short story in the same vein is "All The Myriad Ways" by Larry Niven (available in a collection of stories with the same title). 